\title{
A sea lamprey glycoprotein hormone receptor similar with gnathostome thyrotropin hormone receptor
}

\author{
Mihael Freamat and Stacia A Sower \\ Department of Biochemistry and Molecular Biology, University of New Hampshire, 46 College Road, Room 310, Durham, New Hampshire 03824, USA \\ (Correspondence should be addressed to S A Sower; Email: sasower@ cisunix.unh.edu)
}

\begin{abstract}
The specificity of the vertebrate hypothalamic-pituitary-gonadal and hypothalamic-pituitary-thyroid axes is explained by the evolutionary refinement of the specificity of expression and selectivity of interaction between the glycoprotein hormones $\mathrm{GpH}$ (FSH, LH, and TSH) and their cognate receptors GpH-R (FSH-R, LH-R, and TSH-R). These two finely tuned signaling pathways evolved by gene duplication and functional divergence from an ancestral $\mathrm{GpH} / \mathrm{GpH}-\mathrm{R} p a i r$. Comparative analysis of the protochordate and gnathostome endocrine systems suggests that this process took place prior or concomitantly with the emergence of the gnathostome lineage. Here, we report identification and characterization of a novel glycoprotein hormone receptor (IGpH-R II) in the Agnathan sea lamprey. This 781 residue protein was found $\sim 43 \%$ identical with mammalian TSH-R and FSH-R representative sequences, and similarly with these two classes of mammalian receptors it is assembled from ten exons. A synthetic ligand containing the lamprey glycoprotein hormone $\beta$-chain tethered upstream of a mammalian $\alpha$-chain activated the IGpH-R II expressed in COS-7 cells but in a lesser extent than IGpH-R I. Molecular phylogenetic analysis of vertebrate $\mathrm{GpH}-\mathrm{R}$ protein sequences suggests a closer relationship between IGpH-R II and gnathostome thyrotropin receptors. Overall, the presence and characteristics of the lamprey glycoprotein hormone receptors suggest existence of a primitive functionally overlapping glycoprotein hormone/glycoprotein hormone receptor system in this animal.
\end{abstract}

Journal of Molecular Endocrinology (2008) 41, 219-228

\section{Introduction}

The search for the origins of the hypothalamicpituitary-peripheral gland endocrine systems in the closest relatives of vertebrates, the protochordates, resulted in identification of some putative components of the hypothalamic-pituitary-gonadal (HPG) and/or hypothalamic-pituitary-thyroid (HPT) axes in Amphioxus and/or Ciona (Alieva et al. 2005, Delsuc et al. 2006, Sherwood et al. 2006). However, there is limited evidence at this point for their assembling into functional HPG/HPT axes in these organisms. Therefore, the HPT/HPG gland systems are considered to be vertebrate innovations that emerged prior to or concomitantly with the divergence of gnathostomes from the ancestral jawless vertebrates.

The only surviving Agnathans in the actual fauna are the lampreys and hagfishes, often classified into a distinct taxonomic group, the cyclostomes. New paleontological evidence traces the origin of the lamprey lineage to the base of the phylogenetic tree of vertebrates (Gess et al. 2006, Janvier 2006). Formerly considered a 'degenerate' branch of the ancestors of vertebrates, the ostracoderms, the discovery of the fossil remains of an organism surprisingly similar with the lamprey but dating 360 mya in the late Devonian suggests that the cyclostomes diverged from the ancient Agnathans much earlier than usually considered. This discovery places this species in the "living fossil' group and casts a new significance on the results obtained from the study of this organism (Janvier 2006).

During the last few years, many of the lamprey hormones have been isolated and characterized (reviewed in Sower \& Kawauchi 2001, Kawauchi \& Sower 2006). Studies done on sea lamprey reproduction have also provided evidence for the similarity between the neuroendocrine control of reproductive physiology in this Agnathan and the rest of the vertebrates. Two forms of gonadotropin hormone-releasing hormone (GnRH) have been isolated from lamprey brain: lamprey GnRH-I (Sherwood \& Sower 1985), and lamprey GnRH-III (Sower et al. 1993). Both lamprey GnRH decapeptides have been shown by extensive physiological, anatomical, biochemical, and immunological studies (Sower 1989, Bolduc \& Sower 1992, Deragon \& Sower 1994, Gazourian et al. 1997) capable of controlling the reproduction in lamprey and involved also in regulation of the thyroid hormones (Youson \& Sower 2001). A receptor for lamprey GnRH has also been isolated from the sea lamprey pituitary, its sequence determined, and the functional properties of this protein were recently published (Silver et al. 2005). Numerous efforts have been directed towards isolation and characterization of 
the pituitary hormones directly controlling the physiology of the gonads in sea lamprey: the gonadotropin hormone homologs. These efforts led to the identification of a pituitary glycoprotein similar in sequence with the $\beta$-chain of the gnathostome glycoprotein hormones (Sower et al. 2006). Analysis of the molecular phylogenetic data suggests that this molecule is probably an ortholog of the common molecular ancestor of luteinizing hormone (LH), follicle-stimulating hormone (FSH), and thyroidstimulating hormone (TSH) beta subunits and diverged from its gnathostome counterpart before differentiation of the different types of $\beta$ GpHs (Sower et al. 2006). The functional characteristics of this protein and its role in the physiology of lamprey in the context of the wellestablished HPG/HPT axes paradigm are currently being investigated.

The molecular cloning attempts to identify the lamprey glycoprotein hormone receptors resulted in identification, cloning, and characterization of a new member of the GpH-R subfamily (IGpH-R I; Freamat et al. 2006). This protein was found expressed predominantly in the gonad (testicular) tissue of the mature lamprey. Its sequence has a number of features characteristic to the gonadotropin receptors. It was shown also to have low albeit detectable response to mammalian gonadotropin hormones but no response to mammalian thyrotropin. Incidental data obtained during identification of the lamprey GpH-R I suggested the existence of a second receptor from the same protein family in this animal. This paper reports the identification, cloning of the full coding sequence and characterization of a second sea lamprey glycoprotein hormone receptor (lGpH-R II, GenBank AY750689) similar to gnathostome thyrotropin receptors.

\section{Materials and methods}

\section{Animals}

The reproductively mature migrating sea lampreys were collected during their seasonal migration upstream the Cocheco river in Dover, NH, USA. They were transported to the Anadromous Fish and Aquatic Invertebrate Research (AFAIR) facility at the University of New Hampshire where they were kept under a continuous flow of river water at ambient temperature in a large tank until the time of the experiments. The tissue samples were immediately removed, flash-frozen in liquid nitrogen and kept on dry ice prior to their storage at $-80^{\circ} \mathrm{C}$. The conjunctive tissue located on the dorsal side of the jugular vein between gills number 2 and 6 was used for the preparation of the thyroid total RNA for lGpH-R II cloning and RT-PCR experiments. Testes, liver, muscle, intestine, kidney, thyroid, and brain tissues were also sampled and used in RT-PCR assays.

\section{Degenerate PCR and Step-out RACE}

The degenerate primers based on the GLYCHORMONER protein fingerprint were designed as described elsewhere (Freamat et al. 2006). Step-out RACE method was applied as described in Matz et al. (2003). The TTCAAACGCGTTGGCAGGAATC oligo was used as a gene-specific anchor during the first stage of the Stepout RACE, while the GGCATGTTGAGATTGTCAGCCATC and AAACGCGTTGGCAGGAATCAGG were used as gene-specific primers for the second stage of RACE.

\section{Screening the lamprey genomic data and cloning the full coding sequences of IGpH-R II}

The FASTA-formatted base calls from the sea lamprey whole genome sequencing project (http://genome. wustl.edu/genome.cgi? GENOME = Petromyzon \% 20marinus) were downloaded from NCBI trace repository (http://www.ncbi.nlm.nih.gov/Traces/) and indexed for Blast search on the iNquiry bioinformatics server of the University of New Hampshire. The traces database was then screened for the GpH-R similar clones using the 'BLASTN' program with full coding sequence (CDS) or fragments of the lamprey GpH-R I as queries. Blast hits with an identity score lower than $90 \%$ were then used for screening the public NCBI nucleotide databases using translating blast (TBLASTX) for identification of the possible protein similarities.

\section{Tissue expression by RT-PCR}

The one-tube RT-PCR system and AccessQuick RT-PCR system from Promega were used according to the manufacturer's instructions. After DNase treatment (RQ1 DNase, Promega), the tissue-specific total RNA amount was normalized using a relative measure of the RNA amount in each sample obtained by integration of the densitometric curve of a non-denaturing RNA electrophoresis agarose gel. The gene-specific primers were designed based on the sequences of the PCR clones corresponding to the transmembrane domains of lamprey GpH-Rs. Negative control (no reverse transcriptase) PCRs were run for each sample to allow for the detection of the artifacts resulting from amplification of genomic DNA (not shown).

\section{Genomic DNA Southern hybridization}

Lamprey genomic DNA was isolated, blotted, and probed with a 456 bp digoxigenin (DIG)-labeled DNA fragment obtained by amplification of the well conserved ( $\sim 70 \%$ identity score between lamprey GpH-Rs) transmembrane domain of lGpH-R I. Genomic DNA isolation, restriction digest, electrophoresis, blotting, 
hybridization, and chemiluminescent detection were performed as recommended by the Roche DIG system user manual (Roche Applied Science).

\section{Preparation of the IGpH $\beta-\mathrm{hGpH} \alpha$ tethered construct}

The following primers were used for amplification of the lamprey and human glycoprotein hormone sequences. Primer 1 forward for $\mathrm{lGpH} \beta 5^{\prime}$ end (inserts a KpnI cutting site in the $5^{\prime}$ end): ATAGGTACCACCATGGGTCCCCTTCAGCTGTTCCAAC. Primer 2 reverse for $1 \mathrm{GpH} \beta 3^{\prime}$ end (inserts a BamHI recognition site): ATAGGATCCAACCCGGTAGCTGCCCGCAGCTG. Primer 3 forward for hGpH $\alpha 5^{\prime}$ end (encodes the linker peptide GGGSGGGSGGGSGGG downstream a BamHI cutting site at the $5^{\prime}$ end): ATAGGATCCGGAGGAGGAAGTGGTGGAGGATCAGGCGGAGGATCTGGAGGAGGAGCTCCTGATGTGCAGGATTG. Primer 4 reverse, for $\mathrm{hGpH} \alpha 3^{\prime}$ end (inserts an AgeI cutting site at the $3^{\prime}$ end): ATAACCGGTAGATTTGTGATAATAACAAGTACTGC. It does not include the stop codon, allowing the attachment of a $6 \mathrm{X}$ His tag at the $\mathrm{C}$-terminal end of the recombinant protein. After amplification, DNA fragments were isolated from gel, digested with appropriate pair of enzymes, and inserted by double ligation in the pcDNA3.1/V5-His vector (Invitrogen Corp.) linearized by KpnI/AgeI digestion.

\section{Lamprey GpH-Rs functional assays}

Activation of the cAMP signal transduction pathway was estimated in COS-7 cells (ATCC, Manassas, VA, USA) transfected with lGpH-R I and lGpH-R II expression constructs upon stimulation with a tethered lamprey glycoprotein hormone $\beta$-chain $(\mathrm{lGpH} \beta) /$ human glycoprotein hormone $\alpha$-chain $(\mathrm{hGpH} \alpha)$. The pCRE-secreted alkaline phosphatase (SEAP) reporter plasmid (Clontech) containing the gene for the SEAP under the control of the cAMP-responsive element (CRE) was co-transfected with the receptor plasmids and cAMP-dependent signal transduction pathway activation was determined by measuring the activity of the SEAP reporter in the culture medium. The confluent COS-7 cell culture in DMEM (HyClone, Logan, UT, USA) with 10\% FBS (HyClone) was cut with Trypsin (HyClone) and plated in $60 \mathrm{~mm}$ Petri dishes at a cell density of $4 \times 10^{5}$ cells $/ \mathrm{ml}$ in DMEM $10 \%$ FBS the day before transfection. Three hours before transfection the medium was replaced with fresh DMEM 10\% FBS. Lipofectamine 2000 (Invitrogen Corp.) reagent was used accordingly to the manufacturer's instructions for overnight transfection of attached cells with $8 \mu \mathrm{g}$ plasmid mix at 1:7 (w:w) ratio between receptor and reporter. After transfer to 96-well plates and serum starvation, the cultures were stimulated overnight with the $\mathrm{lGpH} \beta-\mathrm{hGpH} \alpha$ tethered glycoprotein hormone construct. The recombinant hormone was obtained from the culture medium of transiently transfected COS-7 cells concentrated by ultrafiltration and diluted in phenol red-free DMEM with BSA and 3-isobutyl-1methylxanthine (IBMX) to a final $1 \mathrm{mg} / \mathrm{ml} \mathrm{BSA}$ and $0 \cdot 2 \mathrm{mM}$ IBMX concentrations. A mock stimulation was run using the culture medium of COS-7 cells transiently transfected with the blank pcDNA3.1/V5-His plasmid, prepared in parallel with the $\mathrm{GpH} \beta-\mathrm{hGpH} \alpha$ sample. The next day, the culture medium was collected and incubated for $20 \mathrm{~min}$ at $65^{\circ} \mathrm{C}$ to inactivate intrinsic alkaline phosphatase. The SEAP activity was estimated from the initial slopes of the progress curves of dephosphorylation of para nitrophenyl phosphate (pNPP, Sigma) $14 \mathrm{mM}$ in diethanolamine (DEA) buffer (1 M DEA, $0.5 \mathrm{mM} \mathrm{MgCl}_{2}$ (pH 9.8)). Reactions were monitored spectrophotometrically at $405 \mathrm{~nm}$ on a microplate reader (BioTek, Winooski, VT, USA) over a period of up to $24 \mathrm{~h}$. Progress curves were constructed from absorbance readings taken at intervals varying between 3 min (start of reaction) and $4 \mathrm{~h}$ towards the end of incubation. The graphs in Fig. 2 show the means from three transfection experiments assayed in duplicate \pm s.E.M. Pairwise means were compared using the GNU R (http://www.rproject. $\mathrm{org} /)$ two sample $t$-test ( $t$-test) function, differences for which $P>0.05$ were considered unsignificant.

\section{Results}

A novel glycoprotein hormone receptor (lGpH-R II) was identified and cloned from the sea lamprey thyroid tissue (Fig. 1a and b). The protein sequence as deduced by virtual translation of the open reading frame (Fig. 3) is 781 residues in length and highly similar with gnathostome GpH-Rs (FSH-R, LH-R, and TSH-R).

lGpH-R II transcripts were detected in thyroid tissue but also in other tissues (gonad, liver, skeletal muscle, gut, and brain; Fig. 1d). The lGpH-R II gene consists of ten exons alternating with nine introns (Fig. 1e). The introns are located exclusively in the predicted extracellular domain of the mature protein and the lengths of the exons 2-9 are identical with lengths of corresponding exons in tetrapod GpH-Rs. The molecular phylogeny of the representative members of the glycoprotein hormone receptor family in vertebrates suggests a close evolutionary relationship between this receptor and the thyrotropin hormone receptor subfamily (Fig. 4).

This is the second glycoprotein hormone receptor identified in this Agnathan. The global identity between the two lamprey GpH-R $(40 \%)$ was found to be lower than the identity score calculated between each of these two receptors and the tetrapod members of this protein family (LH-R, FSH-R, and TSH-R). The lowest identity score was found in respect to the 

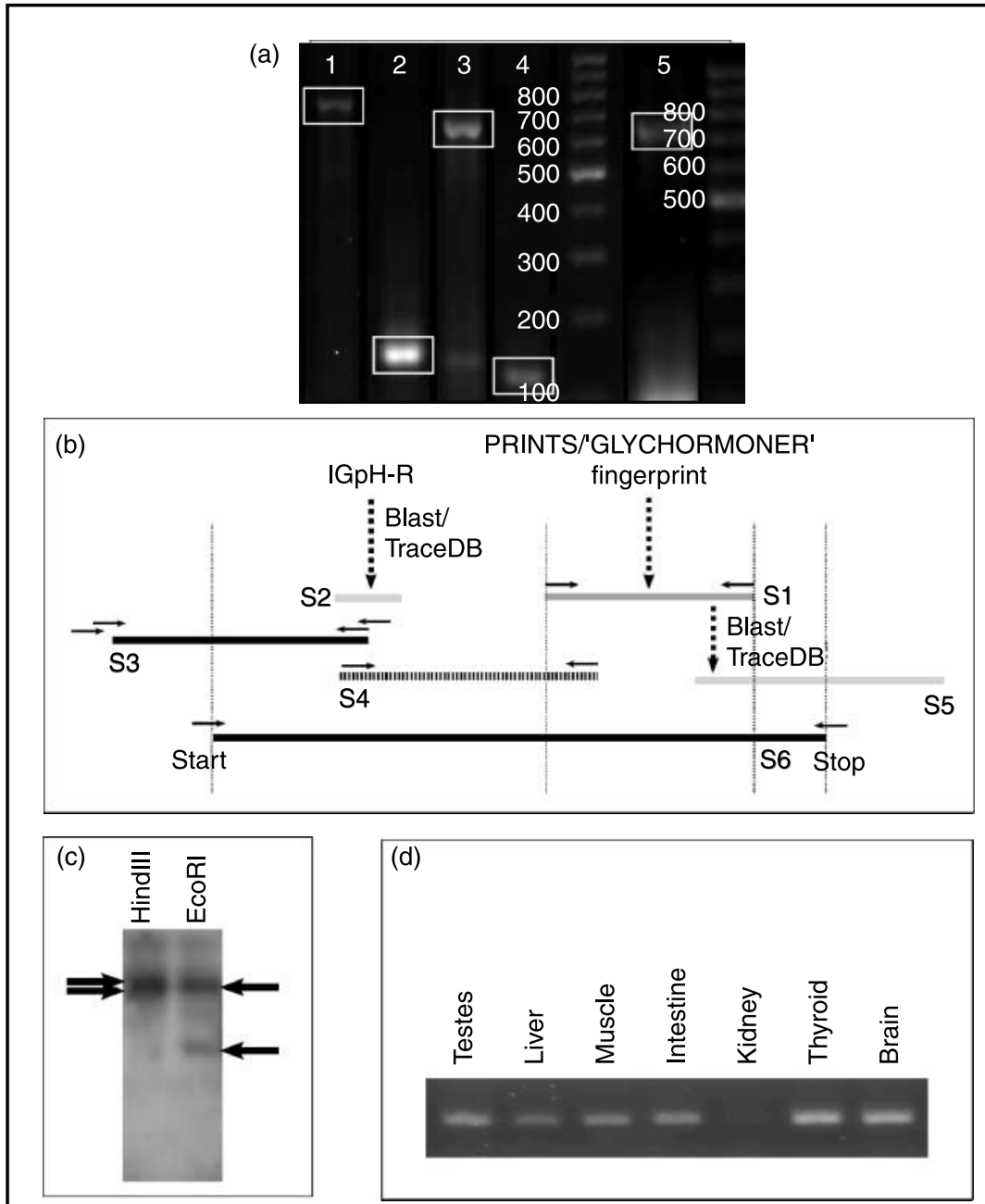

(e)
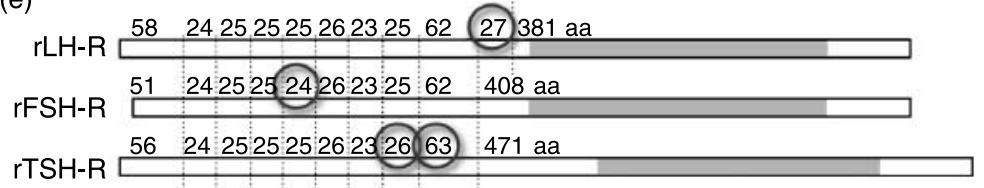

IGpH-RI \begin{tabular}{ll:l:l:l:l}
66 & 24252525262326 & 62 & 418 aa \\
\hline
\end{tabular}

IGpH-R II $58 \quad 2425,25,25,2623,26,62 \quad 488$ aa

Figure 1 Molecular cloning of lamprey GpH-R II. (a) Initial detection of glycoprotein hormones in lamprey testes tissue by PRINTS/GLYCHORMONER fingerprint-based degenerate PCR. (b) The cloning procedure involved a composite approach including DNA fragments identified by degenerate PCR (S1), detected by screening the Petromyzon marinus genomic trace database (S2,S5), identified by Step-out RACE (S3) and obtained by PCR with gene-specific primers (S4). (c) Sea lamprey genomic DNA Southern blot. The genomic DNA was probed with a DIG labeled DNA fragment amplified from the transmembrane domain of IGpH-RI. (d) IGpHR II tissue expression levels by RT-PCR. (e) Genomic organization of lamprey GpH-R II determined by comparison of the IGpH-R I and IGpH-R II CDS with genomic clones in Petromyzon marinus NCBI trace database. Vertical dotted lines mark the exon/exon boundaries; their alignment is based on the sequence annotations. 
teleost GpH-Rs. This is not unexpected since the radiation of fish species was shown to be accompanied by a high frequency of lineage-specific gene duplications and gene loss (Robinson-Rechavi et al. 2001) and consequently by high duplication-dependent substitution rates as well as by substitution rates independent of gene duplication higher than in mammals (Robinson-Rechavi \& Laudet 2001).

The most obvious feature of the coding sequence of $1 \mathrm{GpH}-\mathrm{R}$ II is the presence of a long linker fragment (signalling specific domain, SSD or 'hinge') located in between the Leu-rich domain (LRD) of the extracellular segment (ED) and the transmembrane domain (TMD). This is one of the longest linker fragments described so far in all vertebrate glycoprotein hormone receptors. This is in contrast with the similar region of the lGpH-R I, which is the shortest SSD/hinge segment amongst all vertebrate GpH-Rs (Freamat et al. 2006).

The molecular phylogenetic analysis revealed contradictory phylogenetic signals for functional domains of GpH-Rs (Fig. 4). In a molecular evolutionary context, the phylogenetic signal (Blomberg et al. 2003) describes the tendency of biological sequences to become less similar with increasing time from their divergence by duplication or speciation. The extracellular domain analysis (Fig. 4, ED) predicts the same position of lamprey receptors as a sister group of the thyrotropin receptors. In contrast, the molecular phylogeny derived for the transmembrane domain (Fig. 4, TMD) places lGpH-R I as an out-group of the whole gnathostome GpH-R clade. Each tree can be explained by a hypothetical scenario of gene duplications combined with speciation events resulting in its characteristic topology but a single scenario cannot explain the different topologies of the trees derived for extracellular and transmembrane domains considered separately. The intracellular domains are extremely divergent (identity score with lGpH-Rs varies between 12 and $30 \%$ ), therefore the phylogeny calculated for this segment is likely to have little significance in understanding the evolution of GpH-Rs.

Analysis of the tissue expression pattern by RT-PCR showed a widespread distribution of the presence of lGpH-R II transcripts in the majority of the tissues tested (Fig. 1d).

The genomic DNA Southern hybridization resulted in detection of only two hybridization signals (Fig. 1c). This may suggest that lGpH-R I and lGpH-R II are likely to be the only representative glycoprotein hormone receptors in this species. Extensive blast searches performed with the preliminary lamprey whole genome sequencing data also failed to produce any other genomic clone belonging to a different $\mathrm{GpH}-\mathrm{R}$.

An increase in the constitutive activation of the cAMP-dependent signal transduction pathway as reflected by the activity of the SEAP reporter enzyme in the culture medium was found in COS-7 cells transfected with both IGpH-R I and lGpH-R II constructs (Fig. 2). Activation of this signaling pathway was significant in the cells transfected with the lGpH-R I construct exposed to stimulation by the $\mathrm{GpH} \beta-\mathrm{hGpH} \alpha$ construct. A slight increase in response following the same treatment was also found for lGpH-R II but the difference from basal level is not statistically significant.

\section{Discussion}

We hypothesize that lGpH-R I and lGpH-R II are the only members of the glycoprotein hormone receptor subfamily in lamprey (Fig. 4). They are descendants of the thyrotropin receptor-like molecular ancestors of the $\mathrm{GpH}-\mathrm{Rs}$ in gnathostomes and are likely to be the result of the genome duplication event hypothesized to have taken place before the divergence of lamprey lineage (Sidow 1996, Kuratani et al. 2002).

A long LRD-TMD linker segment, due to the presence of an approximately 50 residue insert, is a

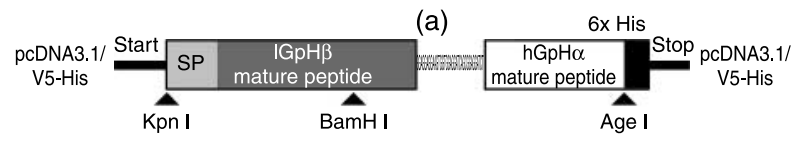

(b)

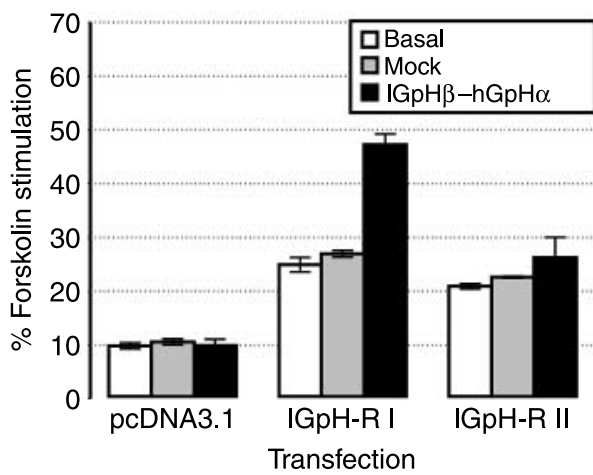

Figure 2 Lamprey glycoprotein hormone receptors functional assay. (a) Diagram of the lamprey $\mathrm{GpH} \beta /$ human $\mathrm{GpH} \alpha$ tethered chimeric hormone used for stimulation of CS-7 cells transfected with lamprey $\mathrm{GpH}-\mathrm{R}$ expression constructs (the $\alpha$-chain of the lamprey $\mathrm{GpH}$ has not yet been identified). (b) Response of COS-7 cells transfected with recombinant IGpH-Rs to lamprey/human chimeric hormone. COS-7 cells were transiently transfected with IGpH-R I, IGpH-R II and an empty pcDNA3.1/V5-His vector. They were exposed overnight to a preparation of $\mathrm{IGpH} \beta / \mathrm{hGpH} \alpha$ hybrid obtained by concentration by ultrafiltration of the serum-free culture medium of a COS-7 culture transiently transfected with the chimeric hormone construct and a mock treatment from a parallel COS-7 culture transfected with the empty vector. The assay signals were normalized in respect to the response of the corresponding cultures to stimulation with a $5 \mathrm{mM}$ forskolin solution and compared with the signal recorded for basal conditions (incubation in the base buffer containing $1 \mathrm{mg} / \mathrm{ml}$ BSA and $0.2 \mathrm{mM}$ IBMX). Results are expressed as percent of forskolin stimulation \pm S.E.M. 
characteristic of the thyrotropin receptors in vertebrates (Farid \& Szkudlinski 2004). This intervening region of TSH-R was shown to have an important role in TSH-R biogenesis being involved in its cleavage and expression on the cell surface as a functional receptor composed of two subunits linked by disulfide bridges (Chazenbalk et al. 1999). The receptor cleavage and reassociation is accompanied by the removal of the 50 residue insert in the ED/TMD linker region (Tanaka et al. 2001). However, the fine details of the mechanisms of this process are not yet fully understood, due primarily to the low similarity between GpH-R paralogs in this region (Farid \& Szkudlinski 2004). In fact, the lowest identity score for lamprey GpH-R II was calculated for the alignments of this region.

Lamprey GpH-R II has seven putative N-glycosylation sites of which four are located in the LRD, two in SSD, and one in intracellular domain (ID). There are no $\mathrm{N}$-glycosylation motifs in the transmembrane domain of lGpH-Rs, in contrast with the mammalian LH-Rs or fish FSH-Rs. The presence of one glycosylation motif in the intracellular domain is characteristic of mammalian FSH-R, TSH-R, and some teleost LH-Rs. The first and the third of the glycosylation motifs in the extracellular domain (Fig. 3) are well preserved in all GpH-Rs. The second motif is also present in teleost gonadotropin receptors while the fourth glycosylation motif of lGpH-R II can only be found in teleost FSH-Rs. The first glycosylation motif in the SSD is common to all GpH-R with the exception of lamprey GpH-Rs, while the second corresponds to the third motif in the SSD of mammalian LH-Rs.

Cysteine residues in the Cys-rich extracellular boxes (CRB) are remarkably conserved: in Fig. 3, the Cys residues present in all GpH-Rs are marked in large fonts on a black background while the third Cys residue in the first C-terminal CRB is represented on a shade of grey to signal the fact that it is only found in FSH-R and TSH-R.

Whereas the length of the protein sequence as well as the global identity score bring the lGpH-R II closer to the tetrapod thyrotropin receptor group, the linker region of this receptor lacks motifs found to be important for the function of TSH-R in these animals. For example, the terminal end of the third Cys-rich box upstream of the first transmembrane segment lacks the Y-[DE]-Y motif related by various authors to a functionally important Y-sulfation in mammalian TSH-Rs (Costagliola et al. 2002). Lamprey gph-r I also lacks this motif and, in this respect, both lamprey glycoprotein hormone receptors resemble the majority of FSH-Rs and teleost LH-Rs suggesting that the functional importance of Y-sulfation is a characteristic acquired later in the evolution of $\mathrm{GpH}-$ Rs in the tetrapod lineages. Moreover, lGpH-R II lacks the TSH-R 'signatures' THIEIRN in the third leucine-rich repeats (LRR) and LKNPQ in SSD and exhibits only a partial (the glycosylation motif at C-terminal end) NISRIY motif at the border between LRR1 and LRR2 (Knudsen \&
Farid 2004). It also lacks the TSH-binding site FDSHY upstream of the second C-terminal CRB and replaces the first lysine in the sixth LRR with arginine, a mutation that was shown in humans to increase sensitivity of TSH-R to chorionic gonadotropin (Smits et al. 2002).

The presence of ten exons in the gene structure of the lamprey GpH-R genes suggests a closer evolutionary relationship between $\mathrm{GPH}-\mathrm{R}$ II and thyrotropin and follitropin receptors in gnathostomes. Lamprey receptors lack the intra-transmembrane domain introns found in some species of teleosts (Oba et al. 2001), as well as the tenth intron in the extracellular domain characteristic to gnathostome LH-R group.

The molecular phylogeny reflects the result of combined functional and evolutionary constraints acting on nucleotide/amino acid sequence change during evolution (Fig. 4). The interacting protein domains in interacting partners (e.g. GpH and GpH-R extracellular domain) are considered exposed to similar functional constraints and consequently will evolve with similar rates (Costagliola et al. 2005), a phenomenon usually termed co-evolution of interacting partners (Moyle et al. 1994). From this perspective, the extracellular domain should reflect to some extent the evolution of the corresponding glycoprotein hormone. It is interesting to note that the only lamprey glycoprotein hormone $\beta$-chain identified to date is not positioned in the TSH molecular phylogenetic cluster but was shown to act as an out-group to the whole vertebrate GpH $\beta$-chain clade (Sower et al. 2006). We do consider, however, that a plausible explanation for the differential evolutionary dynamics of Lgph-r domains are the similar constraints imposed on the extracellular domain by the binding of a common ligand; the transmembrane segment is much less involved in the direct interaction with the hormone and therefore its molecular phylogeny would reflect more accurately the true evolutionary relationships between these proteins.

Analysis of the tissue expression pattern by RT-PCR showed a widespread distribution of the presence of lGpH-R II transcripts in the majority of the tissues tested. This suggests a less stringent transcriptional control of the lGpH-R II gene similarly with lGpH-R I (Freamat et al. 2006), although the distribution of transcript levels of these two receptors in lamprey tissues is different. It has been shown recently that the transcriptional control plays an important role in the functional divergence of members of a protein interacting network, particularly in the context of co-evolution of protein-protein interaction partners (Hakes et al. 2007). The tissue expression pattern of lGpH-R II as well as of Lgph-r are in agreement with a previously described trend of glycoprotein hormone receptors to show a wider tissue distribution in earlier diverged vertebrates (fish) compared with mammals (Oba et al. 2001, Vischer \& Bogerd 2003, Costagliola et al. 2005). 


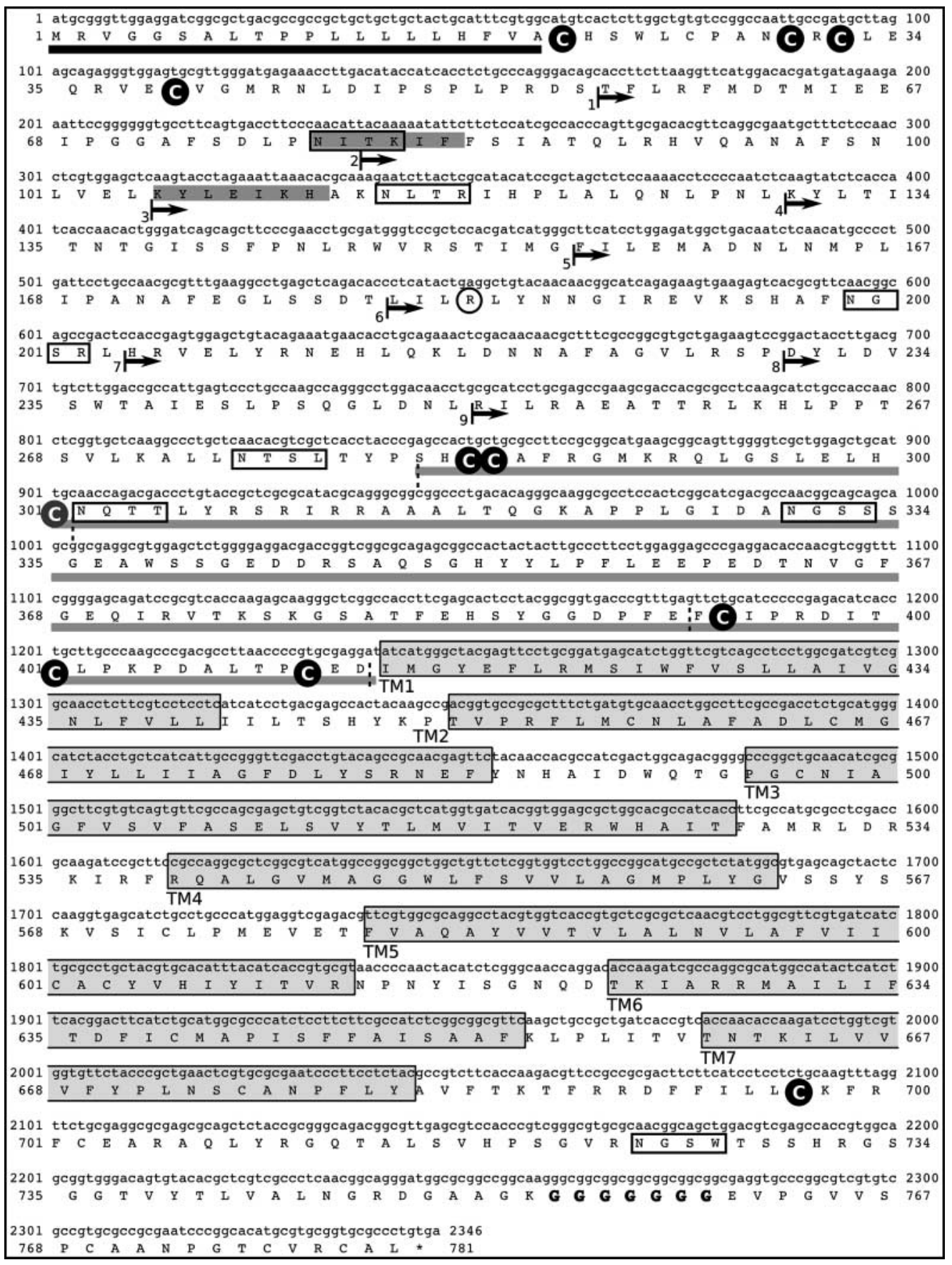

Figure 3 Lamprey GpH-R II sequence and sequence features. Signal peptide is marked by a black solid line. The 'hinge' (SSD) segment is underlined with a grey line and transmembrane segments are marked with grey boxes labeled at the $\mathrm{N}$-terminal end of each segment. The $\mathrm{N}$-terminal ends of the leucine-rich repeats (LRR) are delimited by vertical arrowed lines. Conserved cysteine residues in the Cys-rich boxes of the extracellular domain (bordered by vertical dotted lines) and the intracellular palmitoylation site are signaled by enlarged symbols on black/grey disks. PROSITE glycosylation motifs (N-\{P\}-[ST]-\{P\}) are marked with black rectangles. The Arg residue in the sixth LRR is encircled. The residues on grey backgrounds correspond to the TSH-R signatures in first, second, and third LRR mentioned in text. 

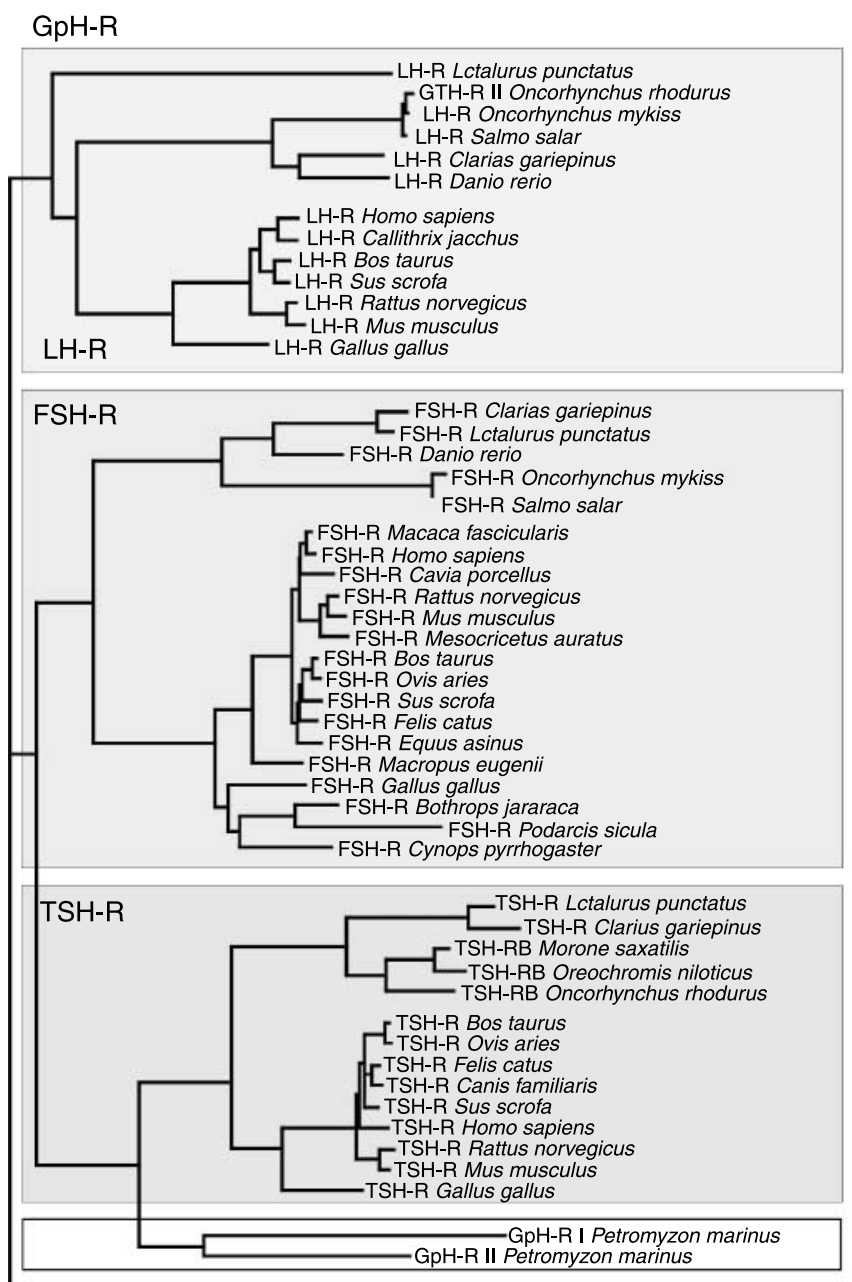

$-0.1$

Figure 4 Molecular phylogeny of vertebrate glycoprotein hormone receptors. The branch lengths were calculated by maximum likelihood for a consensus topology derived from 1000 bootstrap trees calculated using the neighbor-joining method. A reduced $\mathrm{GpH}-\mathrm{R}$ dataset was compared with more distant members of LGR subfamily of GPCRs (upper right panel). The same molecular phylogeny estimation methodology was applied for homologous segments of GpH-Rs corresponding to the major domains (panels labeled ED, TMD, and ID). LGR, leucine-rich repeat G-protein coupled receptors; ED, extracellular domain; TMD, transmembrane domain; ID, intracellular domain.

In summary, lamprey GpH-R II appears as a functional, constitutively active receptor closer in its general properties to the gnathostome TSH-R lineage. It shares many amino-acid sequence motifs with TSH-Rs but lacks sites considered essential for the function of this receptor in the rest of vertebrates. Molecular phylogenies calculated for both the extracellular and transmembrane domains, the most highly conserved regions in this class of proteins consistently place this receptor in the TSH-R clade, in contrast with lGpH-R I. The highest level of its tissue expression was also found in the primitive lamprey thyroid. The gene organization of lGpH-R II, similarly with lGpH-R I is almost identical with the exon/intron structure known for the

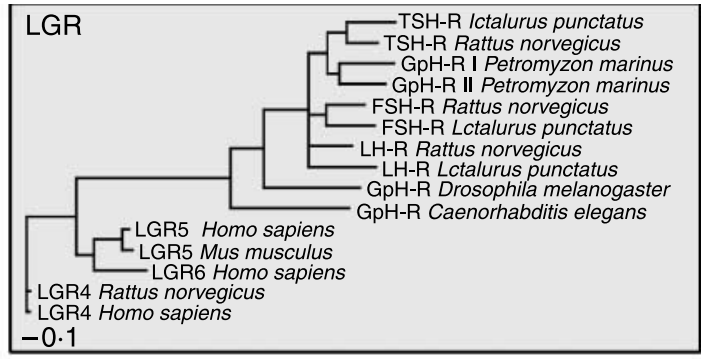

ED

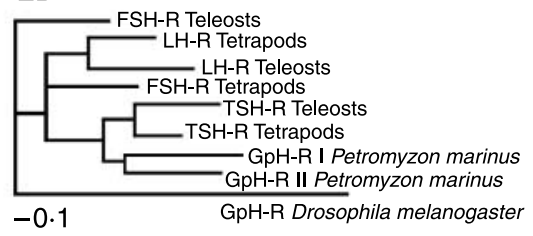

TMD

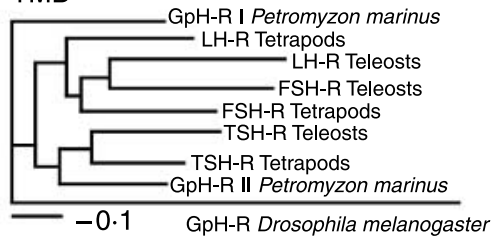

ID

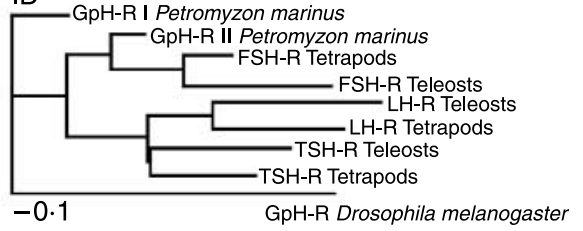

GpH-R Drosophila melanogaster gnathostome TSH-R and FSH-R groups. Overall, IGpH-R II can be described as a thyrotropin receptorlike GpH-R, but this classification should be considered with caution since it bears a functional significance that may not apply entirely to the endocrine physiology of this species.

The experimental findings presented here add new information on the studies to date on the HPG/HPT axes in sea lampreys. On the basis of phylogenetic analysis and molecular studies (Sower et al. 2006), it was proposed that there is only a single gonadotropin hormone in lampreys that did not diverge into FSH and LH in sea lamprey as in gnathostomes. Previous evidence from physiological and immunohistochemical 
studies strongly supported the presence of a GTH-like molecule in lampreys (reviewed in Kawauchi \& Sower 2006). Extensive screening of the lamprey genomic sequences with mammalian or lamprey sequences done in our lab failed to produce any other paralog of $1 \mathrm{GpH} \beta$. Therefore, at this point, a comparative perspective on this endocrine compartment in lamprey relative to the gnathostome well-established paradigm suggests the involvement of one pituitary glycoprotein hormone (only $\beta$-subunit was found) and two glycoprotein hormone receptors as opposed to three or four dimeric hormones and three receptors in gnathostomes. This role of the $\mathrm{GpH} / \mathrm{GpH}-\mathrm{R}$ system in lamprey has yet to be confirmed experimentally. This requires identification and characterization of a $\mathrm{GpH} \alpha$-chain homolog. The existence of a second $\mathrm{GpH}$ ligand in lamprey with a distinct binding specificity to GpH-R I and GpH-R II cannot be excluded, but if it exists it is likely to be even less similar with gnathostome sequences than the one previously described (Sower et al. 2006). The sea lamprey study seems to indicate at this point that in the early stages of their evolution the vertebrate HPG/HPT systems consisted of a reduced number of ligand/receptor pairs, components of an endocrine control hierarchy not very different from that in the modern gnathostomes. It is likely that the existence of primordial, overlapping functional neuroendocrine control pathways of reproductive and thyroid functions in the gnathostome ancestors acted as a structured evolutionary constraint system that determined that the rapid functional divergence of the new genes resulted from subsequent genome duplication events. We predict that further investigation of this system in lamprey will provide valuable insight into an evolutionary process where the specificity of a chemical control pathway undergoes a transition from a predominantly gene expression determinism to the more stable protein-protein interaction selectivity mechanism.

\section{Declaration of interest}

We declare no conflict of interest.

\section{Funding}

This work has been supported by NSF IBN-0421923 to SAS. This is Scientific Contribution number 2342 from the New Hampshire Agriculture Experiment Station.

\section{Acknowledgements}

We thank Dr William Moyle (Robert Wood Johnson Medical School, Piscataway, NJ) for the $\mathrm{hGpH} \alpha$ clone.

\section{References}

Alieva NO, Adams BA \& Tello JA 2005 Endocrinology of protochordates. Canadian Journal of Zoology 83 225-255.

Blomberg SP, Garland T \& Ives AR 2003 Testing for phylogenetic signal in comparative data: behavioral traits are more labile. Evolution $\mathbf{5 7}$ 717-745.

Bolduc TG \& Sower SA 1992 Changes in brain gonadotropin-releasing hormone, plasma estradiol $17-\beta$, and progesterone during the final reproductive cycle of the female sea lamprey, Petromyzon marinus. Journal of Experimental Zoology 264 55-63.

Chazenbalk GD, Tanaka K, McLachlan SM \& Rapoport B 1999 On the functional importance of thyrotropin receptor intramolecular cleavage. Endocrinology 140 4516-4520.

Costagliola S, Panneels V, Bonomi M, Koch J, Many MC, Smits G \& Vassart G 2002 Tyrosine sulfation is required for agonist recognition by glycoprotein hormone receptors. EMBO Journal 21 504-513.

Costagliola S, Urizar E, Mendive F \& Vassart G 2005 Specificity and promiscuity of gonadotropin receptors. Reproduction 130 275-281.

Delsuc F, Brinkmann H, Chourrout D \& Philippe H 2006 Tunicates and not cephalochordates are the closest living relatives of vertebrates. Nature 439 965-968.

Deragon KL \& Sower SA 1994 Effects of lamprey gonadotropinreleasing hormone-III on steroidogenesis and spermiation in male sea lampreys. General and Comparative Endocrinology 95 363-367.

Farid NR \& Szkudlinski M 2004 Minireview: structural and functional evolution of the thyrotropin receptor. Endocrinology 145 4048-4057.

Freamat M, Kawauchi H, Nozaki M \& Sower SA 2006 Identification and cloning of a glycoprotein hormone receptor from sea lamprey, Petromyzon marinus. Journal of Molecular Endocrinology 37 135-146.

Gazourian L, Deragon KL, Chase CF, Pati D, Habibi HR \& Sower SA 1997 Characteristics of GnRH binding in the gonads and effects of lamprey GnRH-I and III on reproduction in the adult sea lamprey. General and Comparative Endocrinology 108 327-339.

Gess RW, Coates MI \& Rubidge BS 2006 A lamprey from the Devonian period of South Africa. Nature 443 981-984.

Hakes L, Lovell SC, Oliver SG \& Robertson DL 2007 Specificity in protein interactions and its relationship with sequence diversity and coevolution. PNAS 104 7999-8004.

Janvier P 2006 Palaeontology: modern look for ancient lamprey. Nature 443 921-924.

Kawauchi H \& Sower SA 2006 The dawn and evolution of hormones in the adenohypophysis. General and Comparative Endocrinology 148 3-14.

Knudsen B \& Farid NR 2004 Evolutionary divergence of thyrotropin receptor structure. Molecular Genetics and Metabolism 81 322-334.

Kuratani S, Kuraku S \& Murakami Y 2002 Lamprey as an evo-devo model: lessons from comparative embryology and molecular phylogenetics. Genesis 34 175-183.

Matz MV, Alieva NO, Chenchik A \& Lukyanov S 2003 Amplification of cDNA ends using PCR suppression effect and step-out PCR. Methods in Molecular Biology 221 41-49.

Moyle WR, Campbell RK, Myers RV, Bernard MP, Han Y \& Wang X 1994 Co-evolution of ligand-receptor pairs. Nature 368 251-255.

Oba Y, Hirai T, Yoshiura Y, Kobayashi T \& Nagahama Y 2001 Fish gonadotropin and thyrotropin receptors: the evolution of glycoprotein hormone receptors in vertebrates. Comparative Biochemistry and Physiology. Part B, Biochemistry and Molecular Biology 129 441-448.

Robinson-Rechavi M \& Laudet V 2001 Evolutionary rates of duplicate genes in fish and mammals. Molecular Biology and Evolution 18 681-683.

Robinson-Rechavi M, Marchand O, Escriva H, Bardet PL, Zelus D, Hughes S \& Laudet V 2001 Euteleost fish genomes are characterized by expansion of gene families. Genome Research 11 781-788.

Sherwood NM \& Sower SA 1985 A new family member for gonadotropin-releasing hormone. Neuropeptides 6 205-214.

Sherwood N, Tello JA \& Roch GJ 2006 Neuroendocrinology of protochordates: insights from Ciona genomics. Comparative Biochemistry and Physiology. Part A. Molecular and Integrative Physiology 144 254-271. 
Sidow A 1996 Gen(om)e duplications in the evolution of early vertebrates. Current Opinion in Genetics and Development 6 $715-722$.

Silver MR, Nucci NV, Root AR, Reed KL \& Sower SA 2005 Cloning and characterization of a functional type II gonadotropin releasing hormone receptor with a lengthy carboxy-terminal tail from an ancestral vertebrate, the sea lamprey. Endocrinology 146 3351-3361.

Smits G, Govaerts C, Nubourgh I, Pardo L, Vassart G \& Costagliola S 2002 Lysine 183 and glutamic acid 157 of the TSH receptor: two interacting residues with a key role in determining specificity toward TSH and human CG. Molecular Endocrinology 16 722-735.

Sower SA 1989 Effects of lamprey gonadotropin-releasing hormone and analogs on steroidogenesis and spermiation in male sea lampreys. Fish Physiology and Biochemistry 7 101-107.

Sower SA \& Kawauchi H 2001 Update: brain and pituitary hormones of lampreys. Comparative Biochemistry and Physiology. Part B, Biochemistry and Molecular Biology 129 291-302.

Sower SA, Chiang YC, Lovas S \& Conlon JM 1993 Primary structure and biological activity of a third gonadotropin-releasing hormone from lamprey brain. Endocrinology 132 1125-1131.
Sower SA, Moriyama S, Kasahara M, Takahashi A, Nozaki M, Uchida K, Dahlstrom JM \& Kawauchi H 2006 Identification of sea lamprey GTHbeta-like cDNA and its evolutionary implications. General and Comparative Endocrinology 148 22-32.

Tanaka K, Chazenbalk GD, Rapoport B \& McLachlan SM 2001 Reassessment of the location of the thyrotropin receptor 50 amino acid 'insertion' provides evidence in favor of a second downstream cleavage site. Thyroid 11 111-114.

Vischer HF \& Bogerd J 2003 Cloning and functional characterization of a gonadal luteinizing hormone receptor complementary DNA from the African catfish (Clarias gariepinus). Biology of Reproduction 68 262-271.

Youson JH \& Sower SA 2001 Theory on the evolutionary history of lamprey metamorphosis: role of reproductive and thyroid axes. Comparative Biochemistry and Physiology. Part B, Biochemistry and Molecular Biology 129 337-345.

Received in final form 16 June 2008

Accepted 30 July 2008

Made available online as an Accepted Preprint 30 July 2008 